\title{
ResearchArticle
}

\section{Chromatic changes in the broccoli stored under modified packaging}

RAKESH KUMAR AND GURDARSHAN SINGH

\section{SUMMARY}

Broccoli was stored under modified atmosphere packaging (MAP) at $15^{\circ} \mathrm{C}$ in perforated and non perforated low density polyethylene (LDPE) and polypropylene (PP) films packages having different head space and in un-sealed packages for a storage period of 10 days to evaluate the effect of modified atmospheres on chromatic changes. At the end of storage, MAP resulted in differential changes in the original green color of broccoli under different packaging treatments. Instead of conventional CIELAB color space system utilizing $\mathrm{L}^{*}, \mathrm{a}^{*}$ and $\mathrm{b}^{*}$ value, the chromatic changes were analyzed as per $\mathrm{L}^{*} \mathrm{C}^{*} \mathrm{~h}^{*}$ colour space system using lightness, chroma, and hue angle values to evaluate final hue (color) along with its associated attributes. On $10^{\text {th }}$ day the result showed that LDPE retained better color than PP films. In non- perforated, the sample become anaerobic after $24 \mathrm{hr}$. Overall at the end of storage, perforated LDPE package having more head space controlled the colour change within human acceptable limits. In comparison, the unsealed packages turned orange yellow compared to MAP. Also the results of sensory evaluation and visual analysis confirmed the results obtained from $\mathrm{L} * \mathrm{C} * \mathrm{~h} *$ color space diagram, and indicated that the modified atmosphere $\left(6.0 \% \mathrm{O}_{2}\right.$ and $\left.7.8 \% \mathrm{CO}_{2}\right)$ generated inside the LDPE perforated packages having 2 holes and 0.8 head space was suitable in maintaining the chromatic quality of the broccoli heads.

Key Words : Broccoli, Storage, Modified packaging, Perforated films

How to cite this article : Kumar, Rakesh and Singh, Gurdarshan (2017). Chromatic changes in the broccoli stored under modified packaging. Internat. J. Plant Sci., 12 (2): 223-233, DOI: 10.15740/HAS/IJPS/12.2/223-233.

Article chronicle : Received : 23.04.2017; Revised : 23.05.2017; Accepted : 14.06.2017 